\title{
Characterizing the Spontaneous Blink Generator: An Animal Model
}

\author{
Jaime Kaminer, ${ }^{1}$ Alice S. Powers, ${ }^{1}$ Kyle G. Horn, ${ }^{2}$ Channing Hui, ${ }^{3}$ and Craig Evinger ${ }^{3,4}$ \\ ${ }^{1}$ Department of Psychology, ${ }^{2}$ Program in Neuroscience, and ${ }^{3}$ Department of Neurobiology and Behavior, SUNY Stony Brook, Stony Brook, New \\ York 11794-5230, and ${ }^{4}$ SUNY Eye Institute
}

\begin{abstract}
Although spontaneous blinking is one of the most frequent human movements, little is known about its neural basis. We developed a rat model of spontaneous blinking to identify and better characterize the spontaneous blink generator. We monitored spontaneous blinking for 55 min periods in normal conditions and after the induction of mild dry eye or dopaminergic drug challenges. The normal spontaneous blink rate was $5.3 \pm 0.3 \mathrm{blinks} / \mathrm{min}$. Dry eye or $1 \mathrm{mg} / \mathrm{kg}$ apomorphine significantly increased and $0.1 \mathrm{mg} / \mathrm{kg}$ haloperidol significantly decreased the blink rate. Additional analyses revealed a consistent temporal organization to spontaneous blinking with a median $750 \mathrm{~s}$ period that was independent of the spontaneous blink rate. Dry eye and dopaminergic challenges significantly modified the regularity of the normal pattern of episodes of frequent blinking interspersed with intervals having few blinks. Dry eye and apomorphine enhanced the regularity of this pattern, whereas haloperidol reduced its regularity. The simplest explanation for our data is that the spinal trigeminal complex is a critical element in the generation of spontaneous blinks, incorporating reflex blinks from dry eye and indirect basal ganglia inputs into the blink generator. Although human subjects exhibited a higher average blink rate (17.6 \pm 2.4$)$ than rats, the temporal pattern of spontaneous blinking was qualitatively similar for both species. These data demonstrate that rats are an appropriate model for investigating the neural basis of human spontaneous blinking and suggest that the spinal trigeminal complex is a major element in the spontaneous blink generator.
\end{abstract}

\section{Introduction}

Spontaneous blinking is one of the most frequent human movements. At an average rate of $\sim 14$ blinks per minute when looking straight ahead (Doughty, 2001), people make $\sim 14,000$ spontaneous blinks during a waking day. Because maintaining corneal tear film requires only three to four blinks per minute (Al-Abdulmunem, 1999), many more blinks are made than necessary to maintain corneal moisture. Given that the main purpose of the eyelids and blinking is to maintain the corneal tear film (Sibony and Evinger, 1998; Evinger, 2010), it is not surprising that corneal afferent inputs modify spontaneous blinking. The blink rate increases with ocular irritation and decreases with corneal anesthesia (Ponder and Kennedy, 1927; Tsubota and Nakamori, 1995; Tsubota et al., 1996; Nakamori et al., 1997; Zaman et al., 1998; Schlote et al., 2004; Naase et al., 2005; Borges et al., 2010). Nevertheless, spontaneous blinking is not simply a reflection of corneal afferent inputs (Acosta et al., 1999; Al-Abdulmunem, 1999) because the kinematics of trigeminal reflex blinks are significantly different from those of spontaneous blinking (Evinger et al., 1991) and corneal and conjunctival anesthesia does not eliminate spontaneous blinking (Naase et al., 2005).

\footnotetext{
Received Nov. 29, 2010; revised May 25, 2011; accepted June 1, 2011.

Author contributions: A.S.P. and C.E. designed research; J.K., A.S.P., K.G.H., C.H., and C.E. performed research; J.K., A.S.P., K.G.H., C.H., and C.E. analyzed data; J.K., A.S.P., K.G.H., and C.E. wrote the paper.

This work was supported by NIH Grant EY07391 to C.E. We thank Michael Ryan for helpful comments on this manuscript and assistance with the experiments.

Correspondence should be addressed to Craig Evinger at the above address. E-mail: levinger@notes.cc.sunysb.edu. DOI:10.1523/JNEUROSCI.6218-10.2011

Copyright $\odot 2011$ the authors $\quad 0270-6474 / 11 / 3111256-12 \$ 15.00 / 0$
}

Nonophthalmic processes also modify spontaneous blinking. Brain dopamine levels modify spontaneous blinking such that reduced dopamine levels decrease blink rate and elevated dopamine levels increase the blink rate (Karson et al., 1981b, 1982a, 1983; Karson, 1983; Lawrence and Redmond, 1991; Kleven and Koek, 1996; Taylor et al., 1999; Korosec et al., 2006). Cognitive states also modify spontaneous blink rate. For example, the average blink rate is lowest during reading and highest during conversation (Ponder and Kennedy, 1927; Fogarty and Stern, 1989; Orchard and Stern, 1991; Doughty, 2001; Pivik and Dykman, 2004).

Thus, spontaneous blinking appears to arise from the activity of an endogenous spontaneous blink generator (Blount, 1927; Ponder and Kennedy, 1927; Stern et al., 1984; Karson, 1988; Naase et al., 2005) that is modulated by corneal afferents, dopamine, and cognitive states. Other than blink rate, however, the properties of the spontaneous blink circuit have not been characterized and its location is unknown. To understand how cognitive processes and disease states modify spontaneous blinking, it is critical to develop a mammalian animal model with which to identify the neural circuits responsible for generating spontaneous blinks.

Rodents provide an excellent model system to identify the neural bases for spontaneous blinking. The characteristics of rodent and human reflex blinking are qualitatively similar (Pellegrini et al., 1995; Powers et al., 1997; Schicatano et al., 2000), and basal ganglia modulation of trigeminal reflex blinks is identical in primates and rats (Basso et al., 1993, 1996; Basso and Evinger, 1996; Gnadt et al., 1997). To characterize the rat spon- 
taneous blink generator, we monitored spontaneous blinking for periods of $1 \mathrm{~h}$ and determined the temporal organization of spontaneous blinking under normal conditions, dry eye, and dopaminergic challenges. Finally, we compared these data with human spontaneous blinking.

\section{Materials and Methods}

Subjects

Spontaneous blinking was monitored in 11 male Sprague Dawley rats $(200-600 \mathrm{~g})$ maintained on a reversed $12 \mathrm{~h}$ light/dark cycle and fed ad libitum. All rat data were collected during the rats' subjective night. Ten human subjects (aged 21-61, 7 female and 3 male) also participated in the study. These subjects gave informed consent for their participation. Other than refractive errors, none of the human subjects had any history of eye abnormality or neurological disease. All experiments were performed in accordance with Federal, State, and University regulations regarding the use of humans and animals in experiments and received approval of the University Institutional Review Board and the Institutional Animal Care and Use Committee.

\section{Procedures}

Rats. Under general anesthesia (ketamine $90 \mathrm{mg} / \mathrm{kg}$, xylazine $10 \mathrm{mg} /$ $\mathrm{kg}$ ), rats were prepared for chronic recording of the orbicularis oculi EMG (OOemg) and stimulation of the supraorbital branch of the trigeminal nerve (Dauvergne and Evinger, 2007). OOemg recordings were performed with a pair of Teflon-coated stainless steel wires $(0.003$ inch diameter bare, 0.0055 inch coated; A-M Systems) implanted into the orbicularis oculi muscle near the lateral canthus. Rats received analgesics for $24 \mathrm{~h}$ after the surgery (Ketorolac, $7 \mathrm{mg} / \mathrm{kg}$ ). Rats were alert and eating within $24 \mathrm{~h}$ of the surgery, but at least 1 week passed before the experiments began. In addition to using the OOemg to monitor the occurrence and size of spontaneous blinks, we also recorded lid movements with an infrared detector (Weiss and Disterhoft, 2008) to corroborate blinks in some rats (see Fig. 1). As there was no difference between blink patterns determined with OOemg recordings and infrared recordings, we combined these data in group analyses. Although supraorbital nerve stimulation was not used in these experiments, the rats participated in subsequent experiments that involved evoking reflex blinks with supraorbital nerve stimulation.

In five of the rats, we collected several days of control data and then produced a unilateral dry eye condition. Rats were anesthetized and the exorbital lacrimal gland (Lorber, 1993; Walcott et al., 2005) ipsilateral to the OOemg electrodes was removed to create a unilateral dry eye. This mild dry eye did not produce corneal ulcerations because rats have two additional glands that contribute to the aqueous portion of the tear film (Williams, 2002). Rats received postoperative analgesics. Spontaneous blink recordings began 2-5 d after the exorbital gland surgery. For these rats, spontaneous blinking was compared within subjects before and after dry eye.

We monitored spontaneous blinking before and after treatment with apomorphine or haloperidol in three rats not used in the dry eye experiments. After collecting $1 \mathrm{~h}$ of spontaneous blinking, the rats received a subcutaneous injection of $0.1 \mathrm{mg} / \mathrm{kg}$ haloperidol (Research Biochemicals) in 10\% ascorbic acid in water, $1 \mathrm{mg} / \mathrm{kg}$ apomorphine hydrochloride (Sigma) in saline, or saline. Ten minutes after drug injection, we collected another hour of spontaneous blinking.

Humans. After acquiring informed consent, an eyelid measuring system was attached to human subjects. To use the magnetic search coil system, the subjects sat in a Helmholtz coil with their head stabilized by a chin rest. A $2 \mathrm{~mm}$ diameter coil was taped onto the center of the lower margin of the upper eyelid (Evinger et al., 1991). Great care was taken to ensure that subjects did not find the coil uncomfortable or irritating. Particularly for subjects with an epicanthal fold, we used an infrared system for measuring eyelid movements (ASL model 210 Eye Tracking System). With sensor adjustment, the infrared monitor provided an accurate measure of upper eyelid position (see Fig. 1).

Data collection and analysis

Spontaneous blinks were monitored in rats as they moved freely in their home cage in a darkened room during their subjective night. Rat OOemg and lid position were recorded for $1 \mathrm{~h}$. With humans, eyelid position was recorded while the subjects watched one of several films lacking strong emotional content. The screen was $1.5 \mathrm{~m}$ in front of the subject at eye level. Lid position was recorded continuously for at least $27 \mathrm{~min}$. Lid position signals were amplified and filtered from DC-300 Hz. All data were sampled at $2 \mathrm{kHz}$ per channel (Data Translation; 12-bit analog-todigital resolution) and stored for later analysis using laboratory developed software. Although spontaneous blinking was recorded for at least $60 \mathrm{~min}$ in rats and $27 \mathrm{~min}$ in humans, we did not analyze the first $5 \mathrm{~min}$ of data in rats or the first 3 min of data in humans to enable subjects to habituate to the experimental situation (Ponder and Kennedy, 1927; Karson et al., 1981a; Naase et al., 2005). Data reported here do not include the habituation period.

We used a variety of mathematical measures to identify and characterize temporal patterns of spontaneous blinking in addition to the typical measures of blink rate and mean and median interblink interval (IBI). For the temporal analysis, we ignored spontaneous blink amplitude and treated each spontaneous blink as a point process, a unitary event that occurred at the start of OOemg activity or lid closure. To identify temporal organization in the pattern of spontaneous blinking, we divided the period of data collection into $1,3,6$, or $10 \mathrm{~s}$ bins and determined the blink rate (blinks/min) for each bin spanning the analysis period. Using MATLAB scripts, we calculated the autocorrelation functions of these binned data to reveal repeating patterns of spontaneous blinking. A fast Fourier transform (FFT) was then performed on the autocorrelation to quantify the frequency components of the spontaneous blinking. We used the Fano factor, normalized variance, to characterize the periodicity of the spontaneous blink pattern further.

We calculated the Fano factor using counting intervals that increased in $1 \mathrm{~s}$ increments. For example, the analysis period was divided into $1 \mathrm{~s}$ bins and the number of blinks occurring in each bin determined. The Fano factor for this counting interval was the variance divided by the mean number of blinks determined over all bins at this counting interval. This calculation was repeated for each counting interval. We plotted the Fano factor as a function of the counting intervals on a log-log plot. The Fano factor provides a measure of whether the variable occurrence of blinks (Fig. 1) matches a Poisson distribution over different time scales (Eden and Kramer, 2010).

To test whether the temporal organization of spontaneous blinks was critical in these measurements, we randomly shuffled the IBI order and recalculated the autocorrelation, FFT, and Fano factor for these randomized blink sequences. Shuffling did not change the mean blink rate or IBI distribution. Results are presented as mean \pm SEM. Statistical analyses used SPSS software.

\section{Results}

\section{Rat spontaneous blinking}

The IBI distribution suggested that the average blink rate failed to characterize spontaneous blinking adequately (Fig. 1). The mean IBI of spontaneous blinking for the 11 rats was $12.6 \pm 0.75 \mathrm{~s}$ calculated over all rats and days of data collection. The IBI distribution, however, did not exhibit a normal distribution as the median IBI was only $4.7 \mathrm{~s}$. To evaluate the IBI distribution for each day of data collection, we determined IBI probability using $0.5 \mathrm{~s}$ bins for each day of data collection for all rats. For rat A, short IBIs had the highest probability, and probability decreased as IBI duration increased (Fig. $2 A$, symbols). Averaging the IBI probability across days provided an estimate of this rat's IBI probability distribution (Fig. $2 \mathrm{~A}$, solid line) and created a metric for comparison among rats. The average IBI probability distribution was similar for all 11 rats (Fig. $2 B$, symbols). Plotting the log of the average of all of the average IBI probabilities as a function of the log IBI revealed power law scaling of IBI probability for IBIs $>0.25 \mathrm{~s}$ (Fig. $2 B$, inset). For IBIs larger than $0.25 \mathrm{~s}$, the equation $c^{\star} \mathrm{IBI}^{\alpha}$ described this power law scaling where $\alpha$ is the scaling factor and $c$ is a constant. As $c$ does not affect the shape of the equation, this value was not considered in our analysis. For rat A, $\alpha$ 


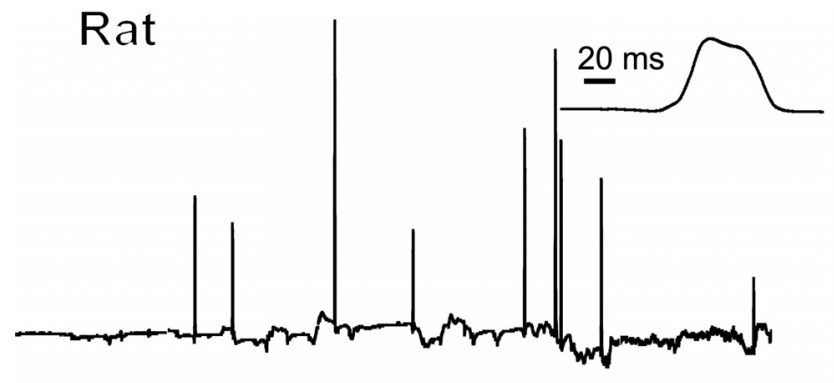

\section{Human}

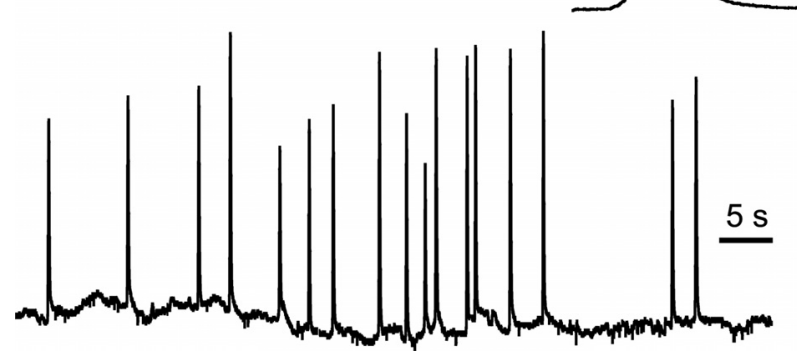

Figure 1. Seventy-five seconds of spontaneous blinking of a rat and a human monitored with infrared eyelid detection. The insets show an individual blink for the rat and the human.

ranged from -0.53 to -0.94 across days. The $\alpha$ value for the averaged IBI probability for each rat ranged from -0.61 to -1.07 .

The increased probability of short rather than long IBIs (Fig. $2 A, B)$ meant that a brief period of data collection should produce a higher blink rate than a long period of data collection. To test this prediction, we calculated the average blink rate in increments of $1 \mathrm{~min}$ for the first $25 \mathrm{~min}$ of data collection after the habituation period for four rats (Fig. 2C). The average blink rate was always higher when averaging across the first $10 \mathrm{~min}$ of data collection than when averaging across all $25 \mathrm{~min}$. For all rats across all days, the average blink rate for $10 \mathrm{~min}$ of data collection $(6.6 \pm 0.5 \mathrm{blinks} / \mathrm{min})$ was significantly higher than the average blink rate with $55 \mathrm{~min}$ of data collection $(5.3 \pm 0.3 \mathrm{blinks} / \mathrm{min}$; $\left.t_{(54)}=5.7, p<0.001\right)$. Consistent with the property of power law distributions, which do not possess means when $\alpha>-2$, the estimate of the spontaneous blink rate was a function of the length of data collection.

The combination of frequent short IBIs with a few long IBIs suggested that spontaneous blinking exhibited periodicity. Plotting the blink rate every $10 \mathrm{~s}$ for $4200 \mathrm{~s}$ of spontaneous blinking revealed such periodicity for rat $\mathrm{E}$ (Fig. $3 A$ ). To identify the temporal organization of the blinks, we performed an autocorrelation on this blink pattern (Fig. 3C). We quantified the periodicity present in the autocorrelation by performing an FFT of the autocorrelation (Fig. 3E). The FFT revealed a dominant frequency of $0.002 \mathrm{~Hz}$, indicating that this pattern of spontaneous blinking repeated every $500 \mathrm{~s}$. To determine whether these calculations resulted from actual temporal patterning, we randomly shuffled the IBI order of these data and repeated the measurements (Fig. $3 B, D, F)$. Shuffling did not affect the blink rate or IBI probability distribution. Nevertheless, shuffling substantially reduced the periodicity revealed by the autocorrelation (Fig. 3D) and the FFT of the autocorrelation (Fig. $3 F$ ). The highest power of the shuffled data (9.2) (Fig. 3F) was less than that of the normal data (20.2) (Fig. 3E) and occurred at a higher frequency (normal: $0.002 \mathrm{~Hz}$, shuffled: $0.00625 \mathrm{~Hz}$ ). Shuffling significantly reduced the FFT peak power determined across all rats and days (normal: $17.1 \pm$
A

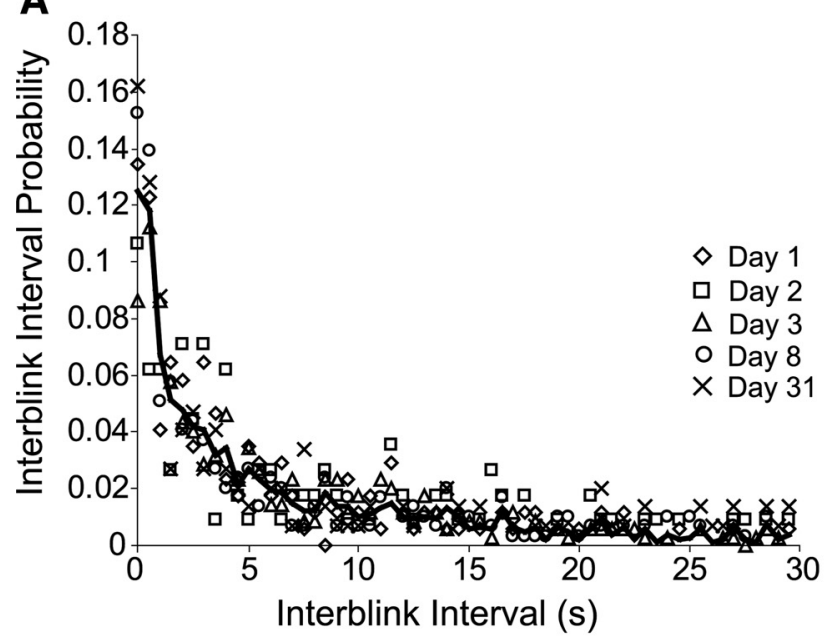

B
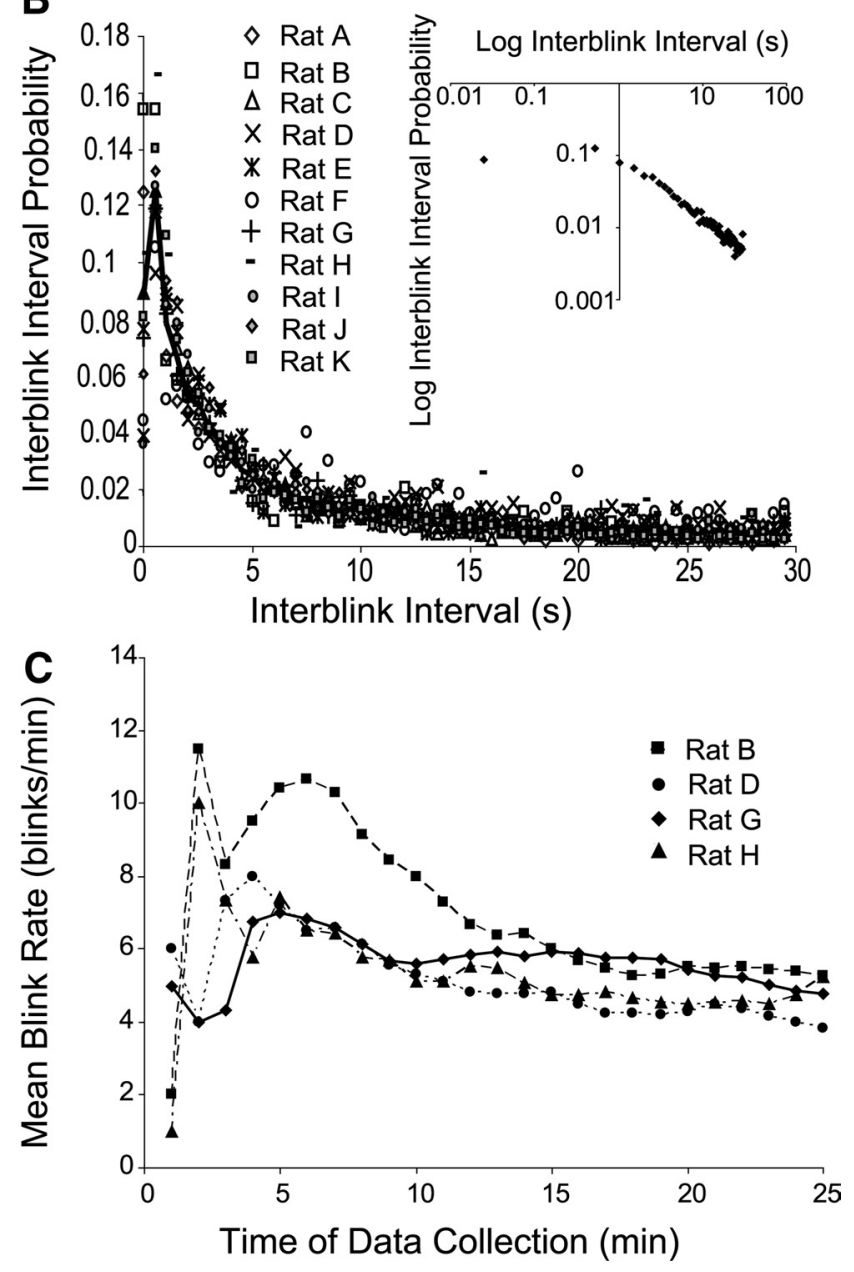

Figure 2. Interblink interval and spontaneous blink rate. $A$, Interblink interval probability distribution calculated in $0.5 \mathrm{sbins}$ for $5 \mathrm{~d}$ of data (open symbols) for rat $A$. The solid line is the average of the probability distribution across days. $\boldsymbol{B}$, Average interblink interval probability distribution across days for 11 rats (symbols) and the average of these distributions (solid line). The inset shows the average probability distribution as a function of interblink interval on a log-log scale. C, Mean blink rate determined in increments of $1 \mathrm{~min}$ for four rats over the first $25 \mathrm{~min}$ of data collection.

1.1; shuffled: $\left.10.3 \pm 0.4 ; t_{(59)}=6.6, p<0.001\right)$. Utilizing $1 \mathrm{~s}$ bins, the frequency at the peak power of the autocorrelation FFT was significantly lower for the normal than for the shuffled data over all rats and days tested $\left(t_{(59)}=-3.1, p<0.005\right)$. Averaged across 


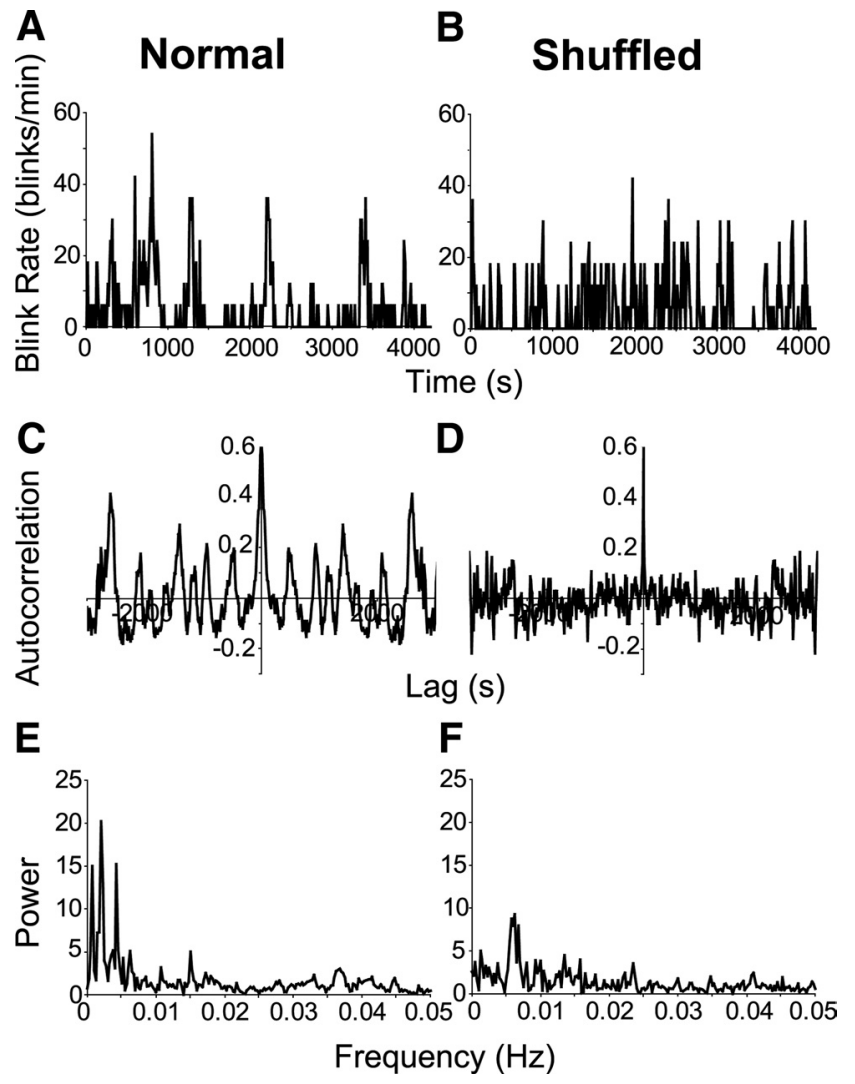

Figure 3. $A$, The blink rate calculated from blinks in $10 \mathrm{~s}$ bins for $4200 \mathrm{~s}$ of spontaneous blinking for rat $E$. $C$, The autocorrelation of the blink rate in $\boldsymbol{A}$ using $10 \mathrm{~s}$ lags. $\boldsymbol{E}$, The power spectrum from the FFT of the autocorrelation in $\boldsymbol{C} . \boldsymbol{B}, \boldsymbol{D}, \boldsymbol{F}$, The blink rate $(\boldsymbol{B})$, autocorrelation $(\boldsymbol{D})$, and power spectrum from the FFT of $\boldsymbol{B}(\boldsymbol{F})$ after randomly shuffling the IBI order of the data in $\boldsymbol{A}$.

animals and days, the pattern of rat spontaneous blinking exhibited a frequency at the peak power of $0.0039 \mathrm{~Hz}$, a 253 s period. The median frequency at the peak power was $0.0013 \mathrm{~Hz}$, a $750 \mathrm{~s}$ period.

For all rats, the log Fano factor for spontaneous blinking increased with the log counting interval (Fig. 4). This result demonstrated that spontaneous blinks were not independent events. If the occurrence of spontaneous blinks followed a Poisson distribution, then the Fano factor would be 1 at all counting intervals (Snedecor and Cochran, 1967). The increasing Fano factor with counting interval was consistent with spontaneous blinking exhibiting periodicity in which blinks were not independent (Fig. 3). Supporting this interpretation, disrupting spontaneous blink periodicity by shuffling significantly reduced the mean exponent of the increase in $\log$ Fano factor from $0.36 \pm 0.02$ to $0.19 \pm 0.01$ $\left(t_{(59)}=11.9, p<0.001\right)$ over all rats and days. Given the importance of periodicity in producing the logarithmically increasing Fano factor, we anticipated that the Fano factor exponent would increase as the regularity of the spontaneous blink periodicity increased (Middleton et al., 2003). When Rat E's autocorrelation FFT revealed strong power over a narrow frequency range (Fig. $4 C$ ), the Fano factor increase was steeper (Fig. $4 A$ ) than on a day when the peak power of the autocorrelation FFT was much less restricted to a narrow frequency (Fig. 4D). The Fano factor exponent increased with the peak power of the autocorrelation FFT across all days and rats (Fig. 4E). Thus, the Fano factor exponent estimated the regularity of the spontaneous blink pattern.

To determine whether the size of bins used to measure blink rate affected the computation of autocorrelation frequency and
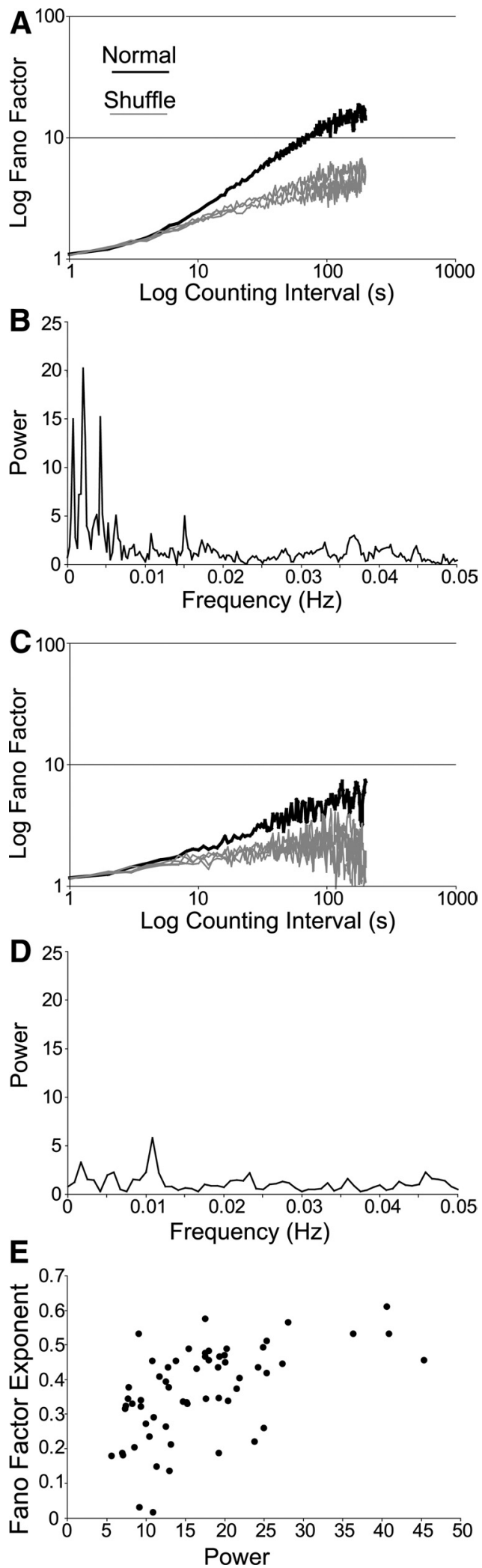

Figure 4. $\quad A, B, \log$ Fano factor as a function of the log counting interval for $2 \mathrm{~d}$ of data from rat E for normal data (black line) and for four shuffles of the normal data (gray lines) $1 \mathrm{~d}(\boldsymbol{A})$ and 15 d later $(\boldsymbol{B}) . \boldsymbol{C}, \boldsymbol{D}$, FFT of the autocorrelation for the blink rate for data from $\boldsymbol{A}$ and $\boldsymbol{B}$ using $10 \mathrm{~s}$ bins. $\boldsymbol{E}$, Plot of the Fano factor exponent as a function of the peak power of the FFT for that day's data for all rats and days. 

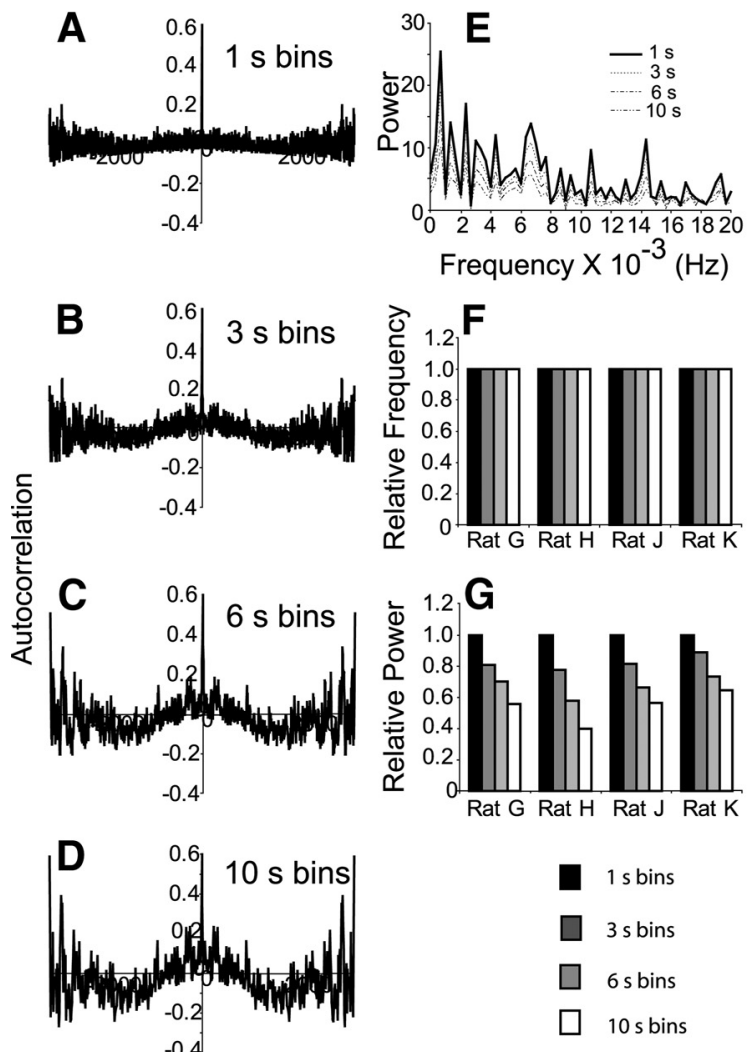

$\operatorname{Lag}(\mathrm{s})$

Figure 5. Effect of bin size on autocorrelations of blink rate $(\boldsymbol{A}-\boldsymbol{D})$, peak frequency $(\boldsymbol{E}, \boldsymbol{F})$, and power of autocorrelations $(\boldsymbol{G})$ for four rats. $\boldsymbol{A}-\boldsymbol{D}$, Autocorrelation of blink rate determined using $1(A), 3(B), 6(C)$, and $10(D) s$ bins for $1 \mathrm{~d}$ of spontaneous blinking of rat $H$. $E$, The power spectrum from FFTs of the autocorrelations illustrated in $\boldsymbol{A}-\boldsymbol{D}$. $\boldsymbol{F}$, The relative frequency at the peak power for FFTs calculated using data binned with $1,3,6$ and $10 \mathrm{~s}$ bins for four rats. $G$, The relative peak power for FFTs calculated using data binned with 1,3,6, and 10 s bins for four rats.

power, we calculated the blink rate, autocorrelation, and FFT of the autocorrelation for the same data from four rats using different sized bins (Fig. 5). Increasing bin size from 1 to 3 to 6 to $10 \mathrm{~s}$ did not change the pattern of the autocorrelation (Fig. 5A-D). The maximum power of the FFT calculated for these autocorrelations decreased with bin size, but the frequency at peak power did not change for this rat (Fig. 5E). For all four rats, frequency at peak power was unaffected by bin size (Fig. $5 F$ ) and peak power decreased with bin size (Fig. $5 G$ ). To use data arrays that most closely approximated individual blink occurrence, all values presented are from calculations using $1 \mathrm{~s}$ bins.

A second potential confound is that spontaneous blink periodicity may be an artifact of the spontaneous blink rate. To resolve this issue, we plotted our measures of periodicity as a function of blink rate. The peak power of the autocorrelation FFT was not correlated with the mean blink rate (Fig. 6A) $(r=0.032)$. Likewise, the frequency at the peak power of the blink pattern was unrelated to the blink rate (Fig. $6 B)(r=0.17)$. Finally, the Fano factor exponent was uncorrelated with the blink rate across all rats and days ( $r=0.2$; data not illustrated). Thus, the periodicity of spontaneous blinking was independent of the spontaneous blink rate.

To test whether rats provided a reliable model for human spontaneous blinking, we characterized rat spontaneous blinking in conditions known to affect human spontaneous blink rates.
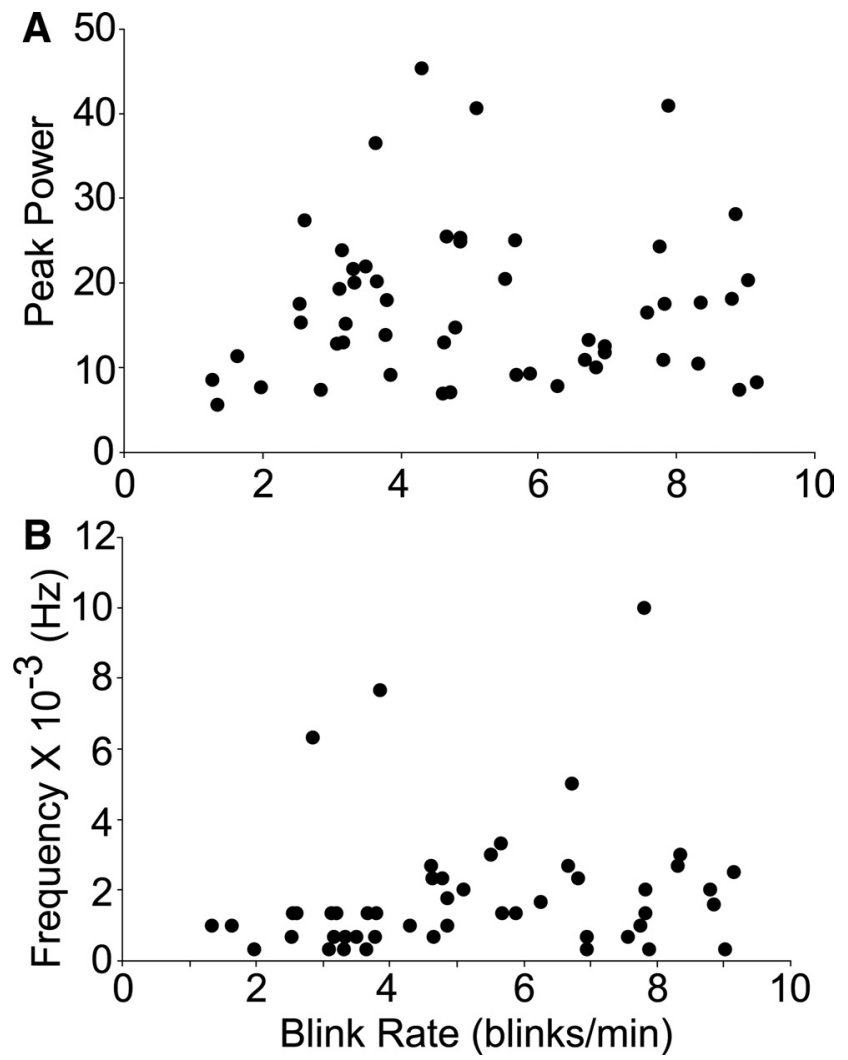

Figure 6. A, Peak power of autocorrelation FFT as a function of blink rate for all rats. Each point is an individual experiment. $r^{2}=0.001$. $B$, Frequency at peak power of autocorrelation FFT as a function of blink rate. Each point is an individual experiment. $r^{2}=0.03$.

Numerous studies demonstrated that dry eye increased the spontaneous blink rate of humans (Tsubota and Nakamori, 1993; Tsubota et al., 1996; Nakamori et al., 1997; Himebaugh et al., 2009). Parkinson's disease, however, decreased spontaneous blink rate (Karson et al., 1982b; Golbe et al., 1989; Deuschl and Goddemeier, 1998; Korosec et al., 2006). In primates, dopaminergic antagonists reduced the blink rate and dopaminergic agonists increased the spontaneous blink rate (Karson et al., 1982a; Karson, 1983; Agostino et al., 1987; Blin et al., 1990; Elsworth et al., 1991; Lawrence and Redmond, 1991; Kleven and Koek, 1996; Taylor et al., 1999). Thus, if rat spontaneous blinking is a model for human blinking, then dry eye and dopamine receptor agonists should increase the blink rate and dopamine receptor antagonists should decrease the spontaneous blink rate of rats.

\section{Dry eye}

Unilateral removal of the exorbital gland significantly increased the spontaneous blink rate of rats as occurs in humans with dry eye. Based on a $3300 \mathrm{~s}$ period of data collection, the mean blink rate increased significantly from $4.8 \pm 0.4$ blinks/min before exorbital gland removal to $6.6 \pm 0.6$ blinks $/$ min afterward $\left(t_{(43)}=\right.$ $2.51, p<0.05)$ for the five rats tested. Dry eye also increased the regularity of spontaneous blinking (Fig. 7). Plotting the spontaneous blink rate over $3300 \mathrm{~s}$ of spontaneous blinking using $10 \mathrm{~s}$ bins revealed stronger periodicity for rat A after dry eye (Fig. $7 B$ ) than before exorbital gland removal (Fig. 7A). Autocorrelations of these instantaneous blink rates (Fig. 7C,D) and FFTs of the autocorrelations (Fig. $7 E, F$ ) confirmed the increased regularity of the blink pattern associated with dry eye. In this example, the peak power of the dry eye FFT was $44 \%$ higher than the peak 

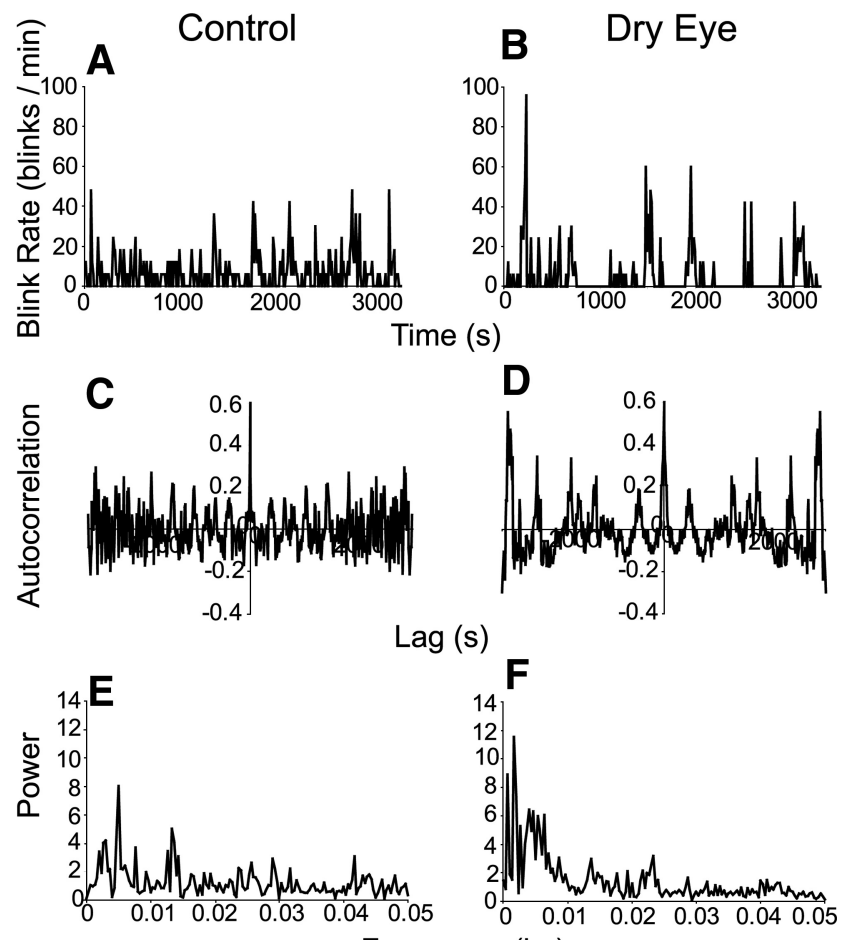

Frequency $(\mathrm{hz})$
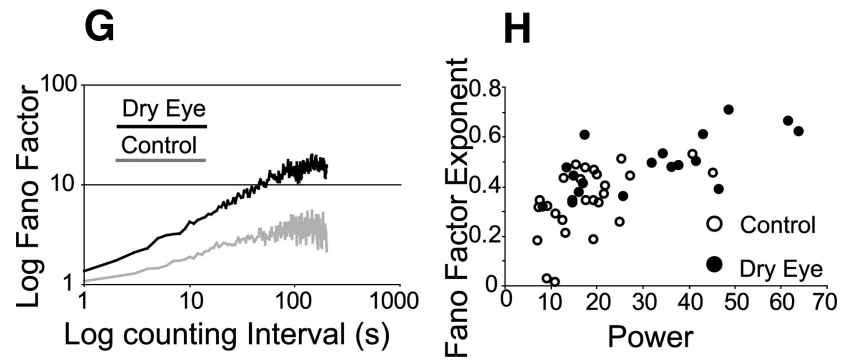

Figure 7. Blink rate $(\boldsymbol{A}, \boldsymbol{B})$, autocorrelation of blink rate $(\boldsymbol{C}, \boldsymbol{D})$, and $\mathrm{FFT}$ of autocorrelations $(\boldsymbol{E}$, F) for $1 \mathrm{~d}$ of data of rat $A$ before (Control) and after (Dry Eye) unilateral removal of the exorbital gland. G, The log Fano factor for data shown in $\boldsymbol{A}$ and $\boldsymbol{B}$ for dry eye (black line) and control (gray line). $\boldsymbol{H}$, The relationship between the exponent of the Fano factor and the peak power of the FFT of the autocorrelation.

power of the control condition. Quantifying the data from all days and rats before and after exorbital gland removal using $1 \mathrm{~s}$ bins confirmed the increase in spontaneous blink periodicity by dry eye. The peak power of the autocorrelation FFT was significantly higher after exorbital gland removal than before dry eye $\left(t_{(43)}=-3.53, p<0.005\right)$. Although the mean frequency at peak power decreased from $0.005 \pm 0.003 \mathrm{~Hz}$ before dry eye to $0.0017 \pm 0.0003 \mathrm{~Hz}$ after exorbital gland removal, this change was not significant $\left(t_{(43)}=1.07, p>0.05\right)$. Consistent with the enhanced regularity of the blink pattern, the Fano factor exponent was significantly higher with dry eye than in control conditions $\left(t_{(43)}=3.83, p<0.001\right)$. Peak power $(r=0.03)$ (Fig. $\left.8 A\right)$, frequency at peak power $(r=0.05)$ (Fig. $8 B$ ), and the Fano factor exponent $(r=0.3)$ (Fig. 8C) were independent of spontaneous blink rate with dry eye. Thus, dry eye significantly increased the spontaneous blink rate and enhanced the regularity of spontaneous blinking. The elevated regularity, however, was independent of the increased blink rate.

The increased blink rate produced from dry eye could result from the occurrence of corneal reflex blinks that were uncorre-
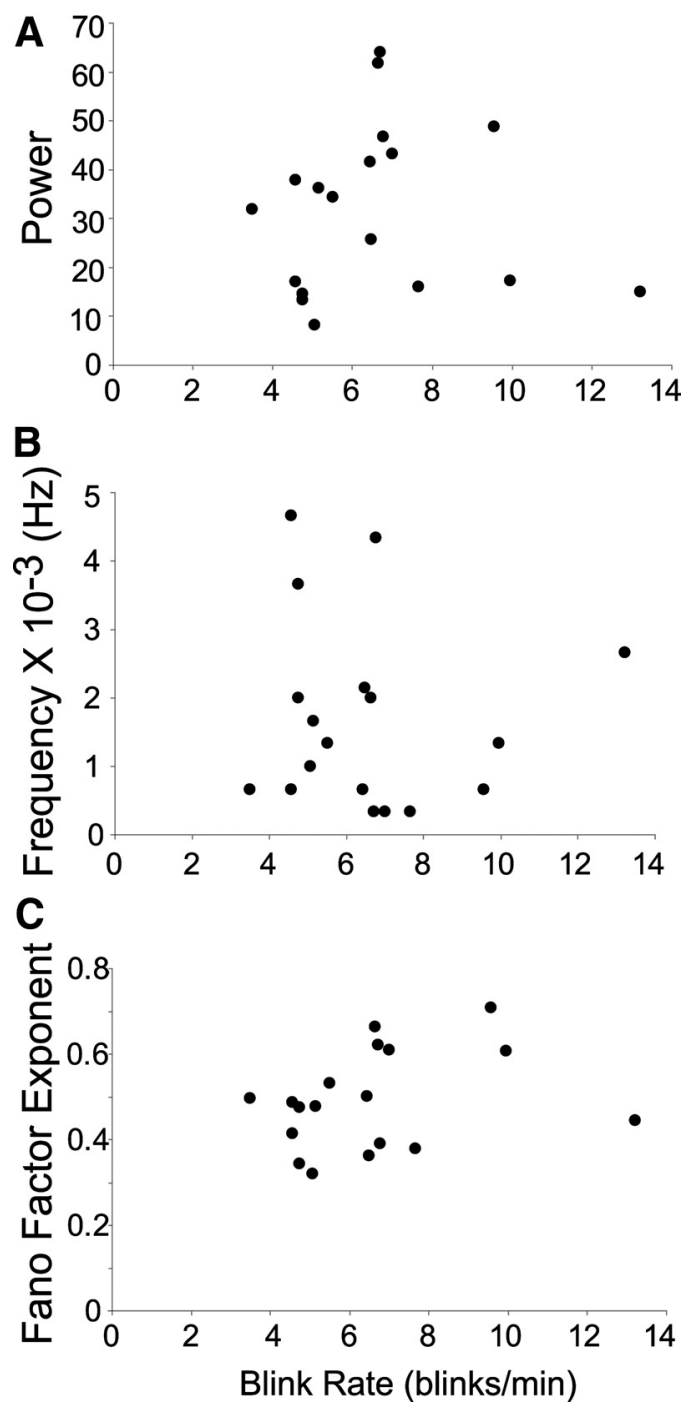

Figure 8. Effects of dry eye on spontaneous blink patterns. A, Peak power of autocorrelation FFT as a function of the mean blink rate for all days and rats with dry eye. Each point is a single experiment. $\boldsymbol{B}$, Frequency of peak power of autocorrelation FFT as a function of the mean blink rate for all days and rats with dry eye. Each point is a single experiment. $\boldsymbol{C}$, Fano factor exponent as a function of the mean blink rate for all days and rats with dry eye. Each point is a single experiment. ${ }^{* *} p<0.005 ;{ }^{* * *} p<0.001$.

lated with the blinks produced by the spontaneous blink generator. Conversely, dry eye could modify the spontaneous blink generator. In the first case, reflex blinks should obscure the periodicity of spontaneous blinks because the occurrence of reflex blinks would be independent of ongoing spontaneous blinks. Our data, however, demonstrated the converse, that dry eye increased the regularity of spontaneous blinking (Fig. 7). Consistent with dry eye modulating the neural circuit that generated spontaneous blinking, the relationship between the autocorrelation FFT peak power and the Fano factor exponent was not significantly different between dry eye and control conditions $(t=-1.4, p>0.05)$ (Fig. $7 H)$. In addition, the frequency at the peak power of the autocorrelation FFT did not change significantly with dry eye. Thus, the data indicated that dry eye modified the spontaneous blink generator to increase blink rate and to enhance its regularity without altering its underlying temporal characteristics. 

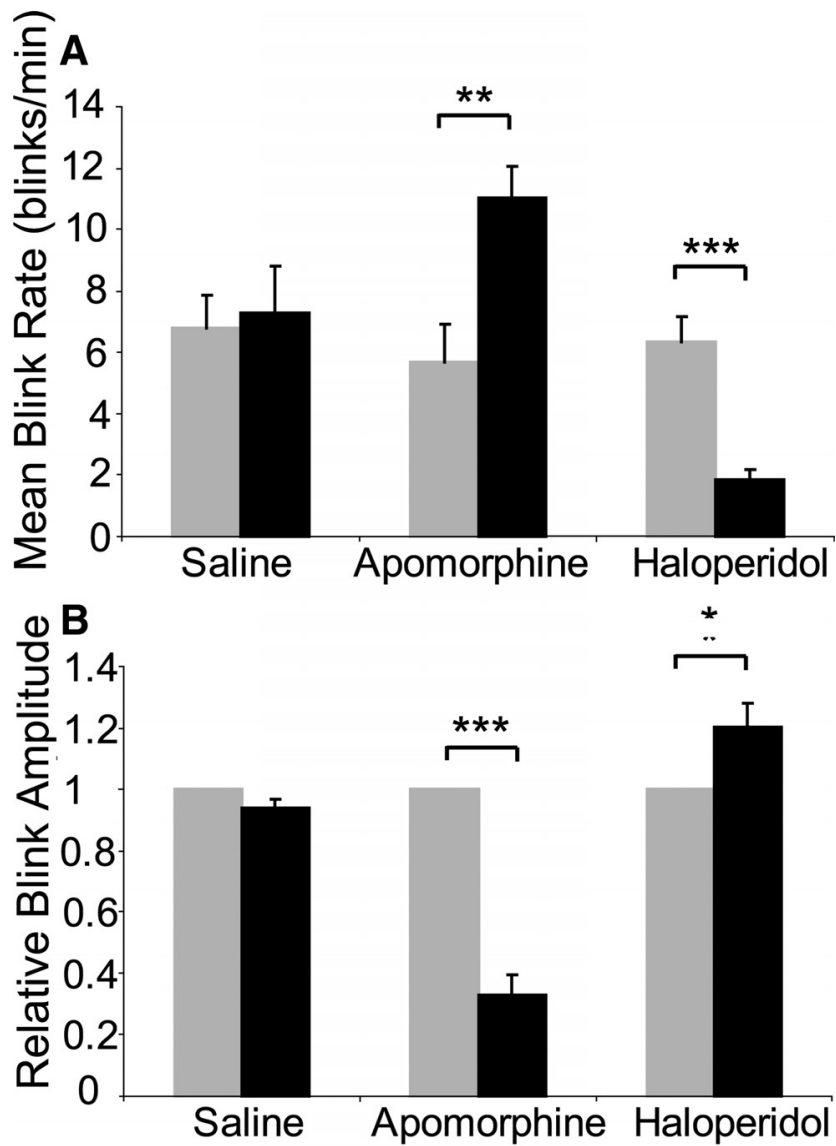

Figure 9. Effects of dopaminergic drugs on spontaneous blinking. $A$, Mean blink rate before (gray bars) and after (black bars) saline, $1 \mathrm{mg} / \mathrm{kg}$ apomorphine, and $0.1 \mathrm{mg} / \mathrm{kg}$ haloperidol. $\boldsymbol{B}$, Blink amplitude relative to blink amplitude before drug treatment, before (gray bars) and after (black bars) saline, $1 \mathrm{mg} / \mathrm{kg}$ apomorphine, and $0.1 \mathrm{mg} / \mathrm{kg}$ haloperidol. ${ }^{*} p<0.05,{ }^{* *} p<0.01$, ${ }^{* * *} p<0.001$

Dopaminergic modulation of spontaneous blinking

Consistent with the decreased blink rate in Parkinson's disease, systemic dopamine antagonists reduced the spontaneous blink rate, whereas dopamine agonists increased the spontaneous blink rate of primates (Karson, 1983; Lawrence and Redmond, 1991; Adamson, 1995; Deuschl and Goddemeier, 1998; Taylor et al., 1999; Hallett, 2000; Esteban et al., 2004; Korosec et al., 2006). If rodent spontaneous blinking models human blinking, then treating rats with haloperidol, primarily a $\mathrm{D}_{2}$ receptor antagonist, should decrease spontaneous blink rate, whereas treatment with apomorphine, a nonselective dopamine receptor agonist, should increase spontaneous blink rate. The data supported this prediction. Treatment with $1 \mathrm{mg} / \mathrm{kg}$ apomorphine significantly raised the blink rate from $5.7 \pm 1.1$ to $11.0 \pm 1.2$ blinks/ $\min \left(t_{(4)}=\right.$ $-5.56, p<0.005$ ) (Fig. 9A). In contrast, treatment with 0.1 $\mathrm{mg} / \mathrm{kg}$ haloperidol significantly reduced the blink rate from $6.3 \pm$ 0.9 to $1.9 \pm 0.3 \mathrm{blinks} / \mathrm{min}\left(t_{(6)}=7.55, p<0.001\right)$ (Fig. $9 A$ ). Injections of saline alone did not significantly alter the spontaneous blink rate (pre $6.8 \pm 1.1$, post $7.3 \pm 1.5 ; t_{(4)}=-0.61, p>$ 0.05 ) (Fig. 9A). Coincident with the change in blink rate, dopaminergic drugs significantly altered blink amplitude. As blink rate increased with apomorphine treatment, the mean spontaneous blink amplitude significantly decreased by $67 \%$ from its pretreatment amplitude $\left(t_{(4)}=11.71, p<0.001\right)$ (Fig. 9B). A 20\% increase in spontaneous blink amplitude $\left(t_{(5)}=-2.8, p<0.05\right)$
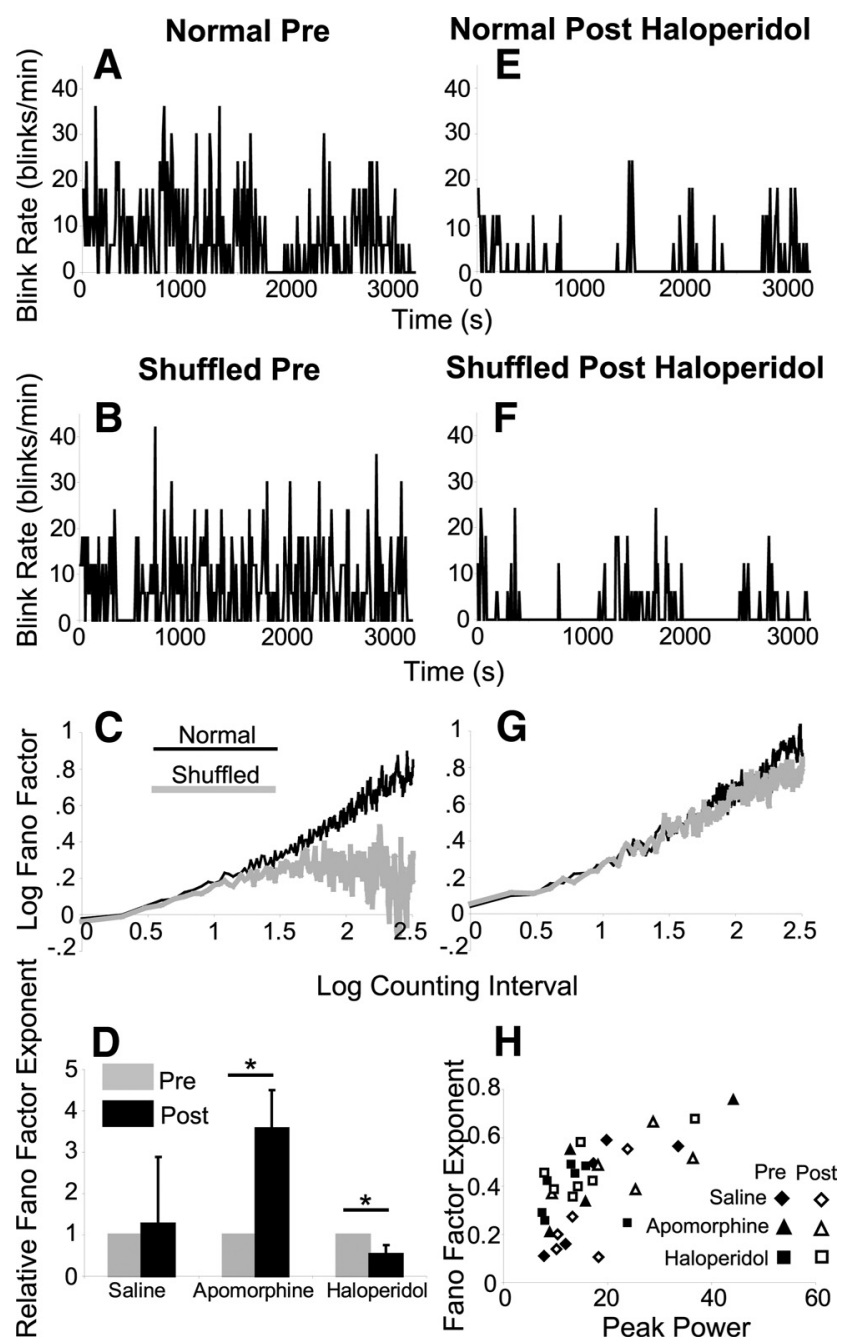

Figure 10. Effect of dopaminergic drugs on spontaneous blinking. $A$, Blink rate in consecutive $10 \mathrm{~s}$ bins for $3200 \mathrm{~s}$ before treatment. $\boldsymbol{B}$, Blink rate in consecutive $10 \mathrm{~s}$ bins for $3200 \mathrm{~s}$ before treatment after randomly shuffling the IBIs from $A$. $C, \log$ Fano factor as a function of $\log$ counting interval for the normal data (black line, $\boldsymbol{A}$ ) and the shuffled data (gray line, $\boldsymbol{B}$ ). $\boldsymbol{D}$, Relative Fano factor exponent before (gray bars) and after (black bars) saline, $1 \mathrm{mg} / \mathrm{kg}$ apomorphine, and $0.1 \mathrm{mg} / \mathrm{kg}$ haloperidol. E, Blink rate in consecutive $10 \mathrm{~s}$ bins for $3200 \mathrm{~s}$ after $1 \mathrm{mg} / \mathrm{kg}$ haloperidol. $\boldsymbol{F}$, Blink rate in consecutive $10 \mathrm{~s}$ bins for $3200 \mathrm{~s}$ with $1 \mathrm{mg} / \mathrm{kg}$ haloperidol treatment after randomly shuffling the IBIs in $E$. G, Log Fano factor as a function of log counting interval for the normal data (black line, $\boldsymbol{A}$ ) and the shuffled data (gray line, $\boldsymbol{B}$ ) after $1 \mathrm{mg} / \mathrm{kg}$ haloperidol. $\boldsymbol{H}$, Fano factor exponent as a function of peak power of the autocorrelation FFT for all animals and days before (open symbols) and after (filled symbols) treatment with saline (224), $1 \mathrm{mg} / \mathrm{kg}$ apomorphine $(\Delta)$, or $0.1 \mathrm{mg} / \mathrm{kg}$ haloperidol $(\square)$. Records in $A-C$ and $\boldsymbol{E}-\boldsymbol{G}$ are data from a single day for one rat. ${ }^{*} p<0.05$.

(Fig. 9B) accompanied the reduction in blink rate produced by haloperidol. As with the absence of changes in blink rate with saline, there was an insignificant $6 \%$ increase in spontaneous blink amplitude $\left(t_{(5)}=2.27, p>0.05\right)$ (Fig. 9B).

To determine whether dopaminergic treatment altered the periodicity of spontaneous blink patterns, we determined the difference between the data and its shuffle for both the predrug and postdrug treatment. We then compared these differences to determine whether dopaminergic drugs affected spontaneous blink periodicity. We adopted this approach because the dramatic reduction in blink rate produced by haloperidol created an artificial periodicity by inserting long periods without blinks within the $3300 \mathrm{~s}$ periods of data collection (Fig. 10). Before haloperidol, the blink rate as a function of time exhibited a nor- 
mal periodicity (Fig. 10A) that random shuffling of the IBIs reduced (Fig. 10B). This loss of periodicity produced by shuffling was clear from the reduction in the Fano factor exponents produced by shuffling (normal pre $=0.42$, shuffled pre $=-0.02$ ) (Fig. 10C). After $0.1 \mathrm{mg} / \mathrm{kg}$ haloperidol, there were episodes of multiple blinks interspersed with prolonged periods without blinks (Fig. 10E). Shuffling the IBIs, however, created apparent periodicity because the brief intervals of blinking were interleaved with those long IBIs without a blink (Fig. 10F). The Fano factor exponents of the normal data (0.45) (Fig. $9 G$ ) and the shuffled IBIs (0.34) (Fig. 10G) were only slightly different, indicating that the apparent periodicity was a result of haloperidol creating multiple long IBIs rather than from changes in the periodicity of the spontaneous blink generator. Comparing the difference between the Fano factor exponent for the obtained and the shuffled IBIs for predrug and postdrug conditions for all animals and days indicated a significant decrease in spontaneous blink regularity produced by haloperidol $\left(t_{(6)}=2.51, p<0.05\right)$ (Fig. $10 D$ ), a significant increase in regularity with apomorphine treatment $\left(t_{(4)}=-3.08, p<0.05\right)$ (Fig. $10 D$ ), but no change following saline injections $\left(t_{(4)}=-0.19, p>0.05\right)$ (Fig. 10D).

As with dry eye, dopaminergic drugs affected spontaneous blink regularity without altering the spontaneous blink period. There were no significant differences between the frequency at the peak power between the three groups before drug treatment $\left(F_{(14)}=1.05, p>0.05\right)$ or after treatment $\left(F_{(14)}=1.24 p>0.05\right)$. There were also no significant differences between the frequency at peak power before and after any drug treatment. The relationship between peak power and the Fano factor exponent remained consistent before (Fig. $10 \mathrm{H}$, open symbols) and after (Fig. $10 \mathrm{H}$, filled symbols) drug or saline treatment. Although activating or blocking dopamine receptors did not affect the periodicity of rat spontaneous blinking, the data revealed that apomorphine enhanced regularity, whereas haloperidol diminished the regularity of spontaneous blinking.

\section{Human spontaneous blinking}

Similar to results of other investigations (Al-Abdulmunem, 1999; Doughty, 2001), we found the average spontaneous blink rate of 10 human subjects was $17.6 \pm 2.4$ blinks/min when monitored for $24 \mathrm{~min}$. Across all subjects, the blink rate ranged from a high of 25.5 to a low of $6.9 \mathrm{blinks} / \mathrm{min}$. The mean IBI was $4.3 \pm 0.8 \mathrm{~s}$. Humans clearly blinked spontaneously more frequently than rats (Fig. 1). Nevertheless, given that the temporal characteristics of rat spontaneous blinking were independent of blink rate (Fig. 6), it was possible that humans and rats exhibited similar temporal patterns to their spontaneous blinking.

As occurred with rodents (Fig. 2), the human IBI probability distribution was not normally distributed. The median human IBI $(2.7 \pm 0.5 \mathrm{~s})$ was lower than the average IBI (Fig. 11A). Plotting the log of the average of all subjects' IBI probabilities as a function of the log IBI revealed power law scaling of IBI probability for IBIs $>1.025 \mathrm{~s}$ (Fig. $11 \mathrm{~B}$ ). The exponent, $\alpha$, for this power law scaling ranged from -1.71 to -0.89 for the 10 subjects, with $\alpha=-1.24$ for the averaged IBI. The power law scaling of the IBI indicated that the mean blink rate depended upon the length of data collection in humans (Fig. 11), as it does in rats (Fig. 2). We plotted the average blink rate as a function of the time of data collection in $1 \mathrm{~min}$ increments for four subjects (Fig. 11C). As occurred with rats, shorter periods of data collection typically produced higher blink rates than did longer periods of data collection. Averaged across all 10 subjects, the blink rate measured over the first $10 \mathrm{~min}$ of data collection was significantly

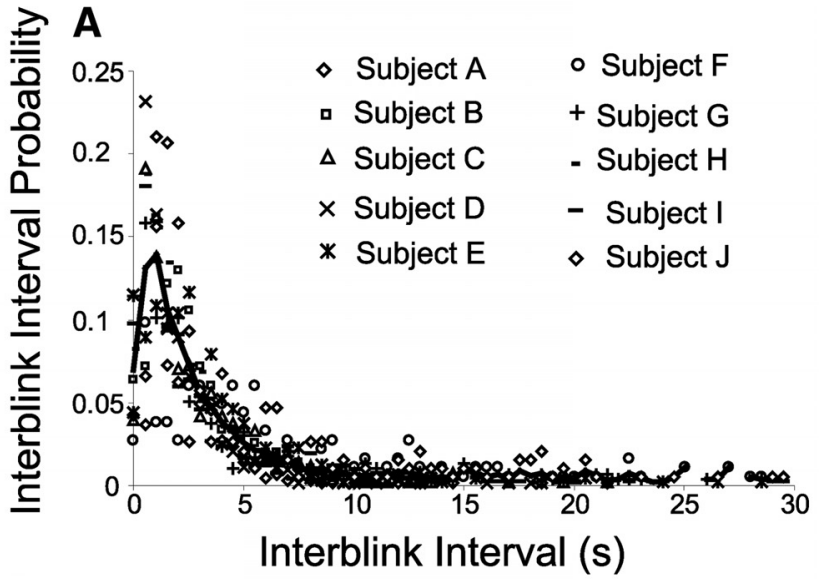

$B$

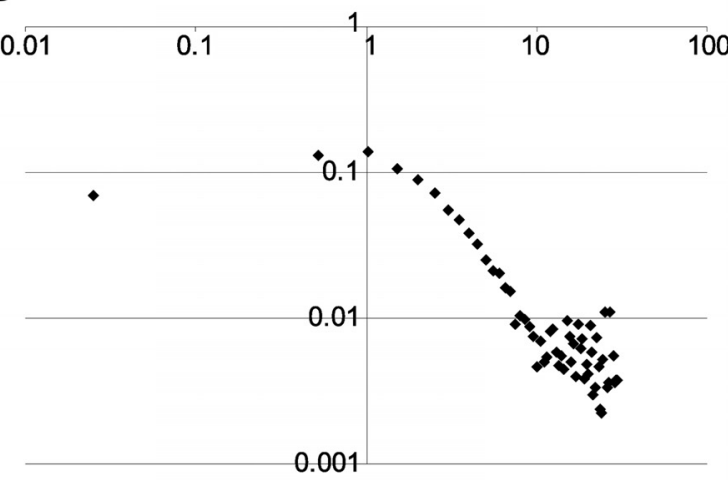

Log Interblink Interval (s)

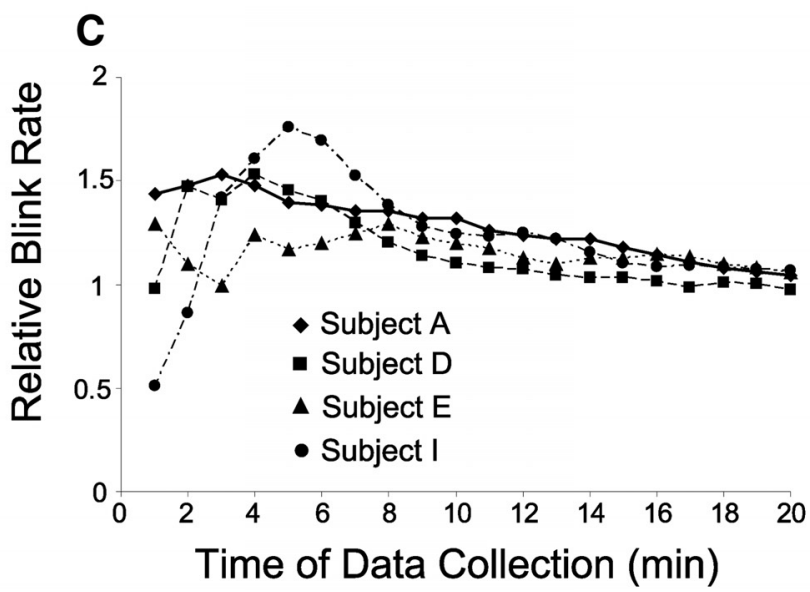

Figure 11. $\quad A$, Interblink interval probability distribution for 10 human subjects (symbols) and the average probability distribution of all subjects (solid line). $\boldsymbol{B}$, Log interblink interval probability of average human data as a function of the log interblink interval. $C$, Mean blink rate determined in increments of $1 \mathrm{~min}$ for four subjects over the first $20 \mathrm{~min}$ of data collection relative to the mean blink rate in the first 24 min of data collection.

higher than that measured over the first 24 min of collection $\left(t_{(9)}=\right.$ $3.19, p<0.05)$.

As in rats, human spontaneous blinking exhibited periodicity (Fig. 12). Calculating the autocorrelation of the blink rate over a 24 min period revealed clear periodicity (Fig. 12A) that was confirmed by performing a FFT on the autocorrelation (Fig. 12B). For the subject illustrated in Figure 12, the frequency at peak power was $0.000833 \mathrm{~Hz}$ (Fig. 12 B). Across all subjects, the mean frequency at the peak power was $0.0055 \pm 0.003 \mathrm{~Hz}$, a period of 

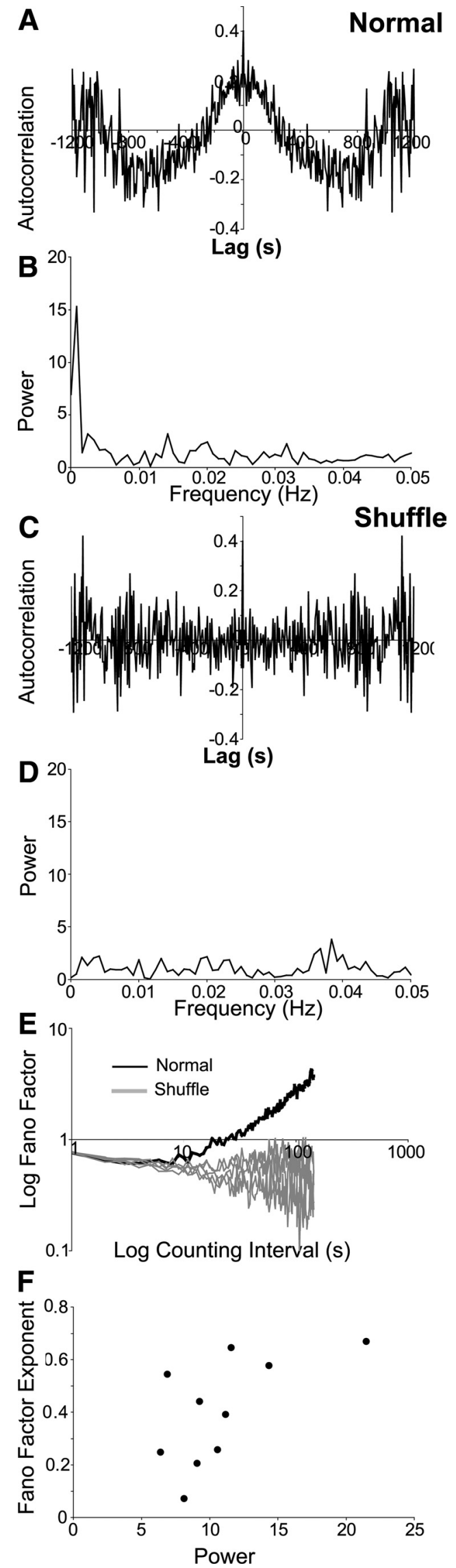

Figure 12. $A, B$, Autocorrelation of normal blinking $(\boldsymbol{A})$ and FFT of the autocorrelation ( $B$ ) using $6 \mathrm{~s}$ bins for subject $A$. $C, \boldsymbol{D}$, Autocorrelation of shuffled data $(\boldsymbol{C})$ and $\mathrm{FFT}$ of the autocorrelation
$180 \mathrm{~s}$. The median frequency was $0.0022 \mathrm{~Hz}$, a $460 \mathrm{~s}$ period. To determine whether this periodicity represented temporal organization, we randomly shuffled the order of the IBIs and calculated the autocorrelation and the autocorrelation FFT of the resulting blink order. For the subject illustrated in Figure 12, shuffling reduced the periodicity revealed by the autocorrelation (Fig. 12C) and the FFT of the autocorrelation (Fig. 12D). For all subjects, the peak power of the shuffled IBIs was significantly less than that of the real data $\left(t_{(9)}=3.05, p<0.05\right)$. As occurred with rats (Fig. 3 ), shuffling significantly increased the frequency at the peak power for humans $\left(t_{(9)}=-2.49, p<0.05\right)$. As with the rat data (Fig. 5), the frequency at peak power of the FFT autocorrelation was independent of the bin size, and the peak power decreased as bin size increased from 1 to 3 to 6 to $10 \mathrm{~s}$ in humans (data not illustrated).

The log Fano factor typically exhibited a constant value of $<1$ between one and five second counting intervals, but steadily increased with higher counting intervals in humans (Fig. 12E). To estimate the increase in Fano factor with the counting interval, we calculated the Fano factor exponent using counting intervals between 10 and $144 \mathrm{~s}$. The Fano factor exponent correlated with the regularity of the spontaneous blink pattern as measured by the peak power of the FFT of the autocorrelation (Fig. 12F). Shuffling the IBI order significantly reduced the Fano factor exponent for all subjects, demonstrating that the increasing Fano factor with counting interval reflected a temporal organization of human spontaneous blinking $\left(t_{(9)}=4.68, p<0.005\right)$.

\section{Discussion}

Although they had significantly different mean IBIs (rats: $12.6 \pm$ $0.75 \mathrm{~s}$; humans: $4.3 \pm 0.8 \mathrm{~s} ; t_{(42)}=-3.74, p<0.001$ ), both species displayed qualitatively similar temporal organization to their spontaneous blink pattern. The IBI distribution exhibited power law scaling (Figs. $1 B, 10 B$ ). When $\alpha>-2$, which is the case for rat and human blinking, it is not possible to determine the blink rate because of power law scaling. This characteristic is consistent with our observation that the mean blink rate depended upon the length of data collection. The higher probability of encountering a short rather than a long IBI caused the estimated spontaneous blink rate to be higher for shorter than for longer periods of data collection (Figs. 2C, 11C). For rats, the mean spontaneous blink rate required at least $15 \mathrm{~min}$ to approach a near plateau level (Fig. $2 C$ ) but continued to decrease slightly throughout the $55 \mathrm{~min}$ recording period. In humans, the blink rate peaked in the first 1-5 min of data collection and then decreased over the next 19 min (Fig. 11C). One possible explanation for this pattern in humans was that the lid coils were mildly irritating until subjects became habituated to their presence. This is unlikely because these data were collected after $3 \mathrm{~min}$ of habituation to the experimental situation and our data were nearly identical to those collected using video cameras (Zaman and Doughty, 1997). We plotted the average blink rate in $1 \mathrm{~min}$ increments relative to the average blink rate after $5 \mathrm{~min}$ of data collection for our 10 subjects and the 14 subjects reported by Zaman and Doughty (1997, their Table 1). Blink rates determined with a lid coil (Fig. 13, -) or a video camera (Fig. 13, $\mathbf{\Delta}$ ) exhibited nearly identical increases over the first 5 min of recording. In our study, however, determining blink

(D) using $6 \mathrm{~s}$ bins. $\boldsymbol{E}$, Log Fano factor as a function of the log counting interval for subject $A$ for normal (black line) and five shuffles (gray lines) of normal data. $\boldsymbol{F}$, Fano factor exponent as a function of peak power. Each point is data from a single subject. 


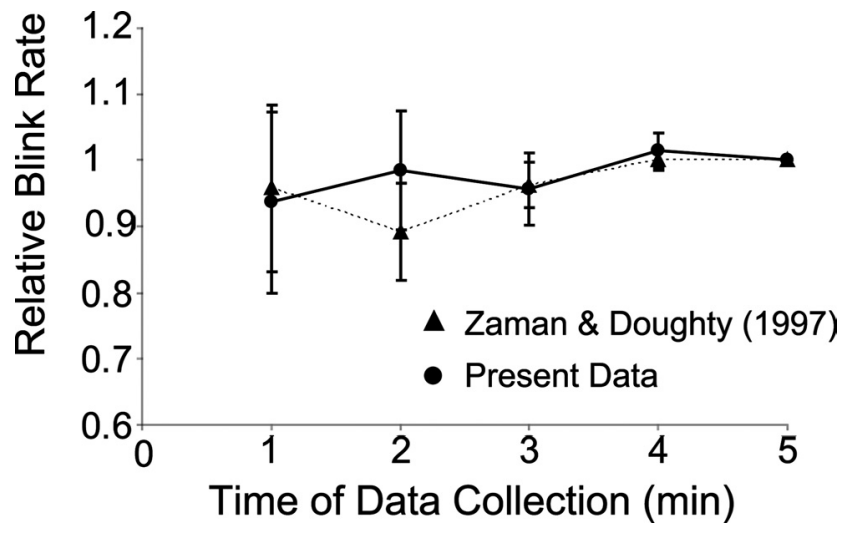

Figure 13. Mean blink rate determined in increments of 1 min for our 10 subjects $(-)$ and 14 subjects from Zaman and Doughty (1997) ( $\mathbf{\Delta})$ over 5 min of data collection relative to the mean blink rate during the first 5 min of data collection.

rates for periods longer than 5 min revealed a steady decline in the rate of human spontaneous blinking (Fig. 11C). Thus, the average spontaneous blink rate depended upon the length of data collection for both rats and humans.

For both species, the pattern of spontaneous blinking revealed long-term periodicity composed of frequent blinking episodes interspersed with interludes of few blinks. An autocorrelation analysis of the blink rate and a FFT of the autocorrelation demonstrated this periodicity (Figs. 3, 12). In rats, the median period for the blink pattern was $750 \mathrm{~s}$, whereas the median blink period was $460 \mathrm{~s}$ for humans. The exponent characterizing the increase in log Fano factor with log counting interval correlated with blink pattern regularity (Figs. 4, 7, 12). The periodicity and regularity identified by the FFT and Fano factor exponent reflected the temporal organization of spontaneous blinking because shuffling the IBI order eliminated or significantly reduced the periodicity in both species (Figs. 3, 4, 12). This temporal pattern was independent of the spontaneous blink rate (Figs. 6, 8). Thus, rat and human spontaneous blinking exhibited similar periodic increases and decreases in blink rate that were independent of the mean blink rate measured over periods of time from 1440 to $3300 \mathrm{~s}$. These similarities demonstrate that the rat is an appropriate animal model for investigating the neural bases of spontaneous blinking.

It is possible that the temporal organization of spontaneous blinking came about from the linkage of blinks to ongoing behaviors rather than ensuing from the activity of a blink generator. Given the numerous influences on spontaneous blink rate involving attention and task (Karson, 1988; Orchard and Stern, 1991; Pivik and Dykman, 2004), the temporal organization determined in humans could reflect changes in attention to the movie storyline that the subjects watched (Nakano et al., 2009). This is unlikely, however, because subjects exhibited similar patterns of temporal organization even though they watched different movies. Moreover, the temporal periodicity of spontaneous blinking exhibited by rats who did not receive patterned external stimulation was not significantly different from that of humans. The simplest explanation of the temporal organization of blinking is that it reflects the action of an endogenous spontaneous blink generator.

Evidence from the present study suggests that the spinal trigeminal complex is an integral component of the spontaneous blink generator circuit. The effects of dry eye on the spontaneous blink pattern is one line of evidence supporting this interpreta- tion. Consistent with previous data from humans (Tsubota et al., 1996; Nakamori et al., 1997), dry eye increases the spontaneous blink rate in rats. The enhanced regularity of the spontaneous blink pattern with dry eye (Figs. 7, 8), however, demonstrates that the elevated blink rate is not due to the uncorrelated addition of corneally evoked reflex blinks to an ongoing spontaneous blink pattern. The blink oscillations associated with corneal irritation may account for the increased regularity of spontaneous blinking with dry eye. Blink oscillations are a series of blinks occurring at a constant interval following a trigeminal blink-evoking stimulus in individuals with corneal irritation (Evinger et al., 2002; Schicatano et al., 2002; Henriquez and Evinger, 2007). They result from the activity of spinal trigeminal neurons (Henriquez and Evinger, 2007). The simplest interpretation for the increased regularity is that the spinal trigeminal complex incorporates corneal reflex blinks and blink oscillations into the pattern of spontaneous blinking in the same way that the swimming central pattern generator incorporates escape responses into the ongoing swim pattern (Svoboda and Fetcho, 1996).

The basal level of corneal afferent input to the spinal trigeminal complex may establish the mean IBI for spontaneous blinking. In humans, tear film break-up begins $\sim 15 \mathrm{~s}$ after completing a blink (Németh et al., 2002; Montés-Micó et al., 2004). Breaks in the tear film expose the corneal surface to air and increase corneal afferent activity (Acosta et al., 2001). Under normal conditions, a spontaneous blink generator should incorporate approximately three to four blinks a minute into the spontaneous blink pattern. Although tear film break-up times are not known for rats, the estimated rat tear film thickness, $11.4-12.6 \mu \mathrm{m}$, is approximately four times that of humans, $3 \mu \mathrm{m}$ (King-Smith et al., 2004). Assuming that a thicker tear film has a longer break-up time than a thinner film, the rat spontaneous blink generator should incorporate fewer corneal blinks per minute into the spontaneous blink pattern than would humans. Consistent with the basal corneal afferent input into the spinal trigeminal nucleus setting the mean IBI, anesthetizing the cornea reduces the spontaneous blink rate in humans (Ponder and Kennedy, 1927; Nakamori et al., 1997; Naase et al., 2005; Borges et al., 2010). Thus, independent of the spontaneous blink pattern, the level of corneal afferent input may set the average IBI (Bacher, 2010).

Dopaminergic modulation of spontaneous blinking (Karson, 1983, 1988; Elsworth et al., 1991; Lawrence and Redmond, 1991; Kleven and Koek, 1996; Taylor et al., 1999) also supports the hypothesis that the spinal trigeminal complex is an essential element of the spontaneous blink generator circuit. Changes in dopamine levels affect spontaneous blinking and trigeminal reflex blinks in a similar fashion. Reduced dopamine levels increase trigeminal reflex blink amplitude and excitability (Basso et al., 1993; Evinger et al., 1993). Likewise, dopamine receptor antagonists increase spontaneous blink amplitude (Fig. 9B). Conversely, treatment with apomorphine, a dopamine agonist, decreases both trigeminal reflex blink (Evinger et al., 1993) and spontaneous blink (Fig. 9B) amplitude. Basal ganglia dopamine levels alter trigeminal reflex blink amplitude and excitability through substantia nigra pars reticulata inhibition of the superior colliculus, superior colliculus excitation of the nucleus raphe magnus, and nucleus raphe magnus inhibition of the spinal trigeminal complex (Basso and Evinger, 1996; Basso et al., 1996; Gnadt et al., 1997). With Parkinson's disease, the elevated activity of the substantia nigra pars reticulata (Wichmann and DeLong, 2003) would reduce nucleus raphe magnus inhibition of the trigeminal complex, thereby increasing blink amplitude and reducing the rate of spontaneous blinking. The opposite result would occur 
with dopamine receptor agonists (Kliem et al., 2007). Similar to the increase in birdsong variability with dopamine depletion and its reduction with elevated dopamine levels (Leblois et al., 2010), increased dopamine levels reduce blink variability and decreased dopamine levels enhance blink variability. Thus, indirect modifications of the spinal trigeminal complex by the basal ganglia can account for changes in spontaneous blink rate (Fig. 9) and variability (Fig. 10) associated with dopamine levels.

The dopamine and dry eye data point to an essential role of the spinal trigeminal complex in the spontaneous blink generator. The spinal trigeminal complex receives a direct corneal afferent input (Panneton and Burton, 1981; Shigenaga et al., 1986; van Ham and Yeo, 1996) and contains the second order neurons of the three-neuron corneal reflex blink circuit (Henriquez and Evinger, 2007) necessary to control mean IBI and incorporate corneal reflex blinks into the spontaneous blink pattern. The basal ganglia regulation of spinal trigeminal activity enables dopamine to modify blink rate and variability. Although the location of the spontaneous blink generator circuit is unknown, the data suggest that the spinal trigeminal complex plays a direct rather than a modulatory role in the circuit.

\section{References}

Acosta MC, Gallar J, Belmonte C (1999) The influence of eye solutions on blinking and ocular comfort at rest and during work at video display terminals. Exp Eye Res 68:663-669.

Acosta MC, Belmonte C, Gallar J (2001) Sensory experiences in humans and single-unit activity in cats evoked by polymodal stimulation of the cornea. J Physiol 534:511-525.

Adamson TA (1995) Changes in blink rates of Nigerian schizophrenics treated with chlorpromazine. West Afr J Med 14:194-197.

Agostino R, Berardelli A, Cruccu G, Stocchi F, Manfredi M (1987) Corneal and blink reflexes in Parkinson's disease with "on-off" fluctuations. Mov Disord 2:227-235.

Al-Abdulmunem M (1999) Relation between tear breakup time and spontaneous blink rate. Int Contact Lens Clin 26:117-120.

Bacher LF (2010) Factors regulating eye blink rate in young infants. Optom Vis Sci 87:337-343.

Basso MA, Evinger C (1996) An explanation for reflex blink hyperexcitability in Parkinson's disease. II. Nucleus raphe magnus. J Neurosci 16:7318-7330.

Basso MA, Strecker RE, Evinger C (1993) Midbrain 6-hydroxydopamine lesions modulate blink reflex excitability. Exp Brain Res 94:88-96.

Basso MA, Powers AS, Evinger C (1996) An explanation for reflex blink hyperexcitability in Parkinson's disease. I. Superior colliculus. J Neurosci 16:7308-7317.

Blin O, Masson G, Azulay JP, Fondarai J, Serratrice G (1990) Apomorphineinduced blinking and yawning in healthy volunteers. Br J Clin Pharmacol 30:769-773.

Blount WP (1927) Studies of the movements of the eyelids of animals: blinking. Exp Physiol 18:111-125.

Borges FP, Garcia DM, Cruz AA (2010) Distribution of spontaneous interblink interval in repeated measurements with and without topical ocular anesthesia. Arq Bras Oftalmol 73:329-332.

Dauvergne C, Evinger C (2007) Experiential modification of the trigeminal reflex blink circuit. J Neurosci 27:10414-10422.

Deuschl G, Goddemeier C (1998) Spontaneous and reflex activity of facial muscles in dystonia, Parkinson's disease, and in normal subjects. J Neurol Neurosurg Psychiatry 64:320-324.

Doughty MJ (2001) Consideration of three types of spontaneous eyeblink activity in normal humans: during reading and video display terminal use, in primary gaze, and while in conversation. Optom Vis Sci 78:712-725.

Eden UT, Kramer MA (2010) Drawing inferences from Fano factor calculations. J Neurosci Methods 190:149-152.

Elsworth JD, Lawrence MS, Roth RH, Taylor JR, Mailman RB, Nichols DE, Lewis MH, Redmond DE Jr (1991) D1 and D2 dopamine receptors independently regulate spontaneous blink rate in the vervet monkey. J Pharmacol Exp Ther 259:595-600.

Esteban A, Traba A, Prieto J (2004) Eyelid movements in health and disease.
The supranuclear impairment of the palpebral motility. Neurophysiol Clin 34:3-15.

Evinger, C (2010) Eyelid anatomy and the pathophysiology of blinking. In: Encyclopedia of the eye (Dartt, DA, ed), pp 128-133. Oxford: Academic.

Evinger C, Manning KA, Sibony PA (1991) Eyelid movements. Mechanisms and normal data. Invest Ophthalmol Vis Sci 32:387-400.

Evinger C, Basso MA, Manning KA, Sibony PA, Pellegrini JJ, Horn AK (1993) A role for the basal ganglia in nicotinic modulation of the blink reflex. Exp Brain Res 92:507-515.

Evinger C, Mao JB, Powers AS, Kassem IS, Schicatano EJ, Henriquez VM, Peshori KR (2002) Dry eye, blinking, and blepharospasm. Mov Disord 17 [Suppl 2]:S75-S78.

Fogarty C, Stern JA (1989) Eye movements and blinks: their relationship to higher cognitive processes. Int J Psychophysiol 8:35-42.

Gnadt JW, Lu SM, Breznen B, Basso MA, Henriquez VM, Evinger C (1997) Influence of the superior colliculus on the primate blink reflex. Exp Brain Res 116:389-398.

Golbe LI, Davis PH, Lepore FE (1989) Eyelid movement abnormalities in progressive supranuclear palsy. Mov Disord 4:297-302.

Hallett M (2000) Clinical physiology of dopa dyskinesia. Ann Neurol 47: S147-S150; discussion S150-S143.

Henriquez VM, Evinger C (2007) The three-neuron corneal reflex circuit and modulation of second-order corneal responsive neurons. Exp Brain Res 179:691-702.

Himebaugh NL, Begley CG, Bradley A, Wilkinson JA (2009) Blinking and tear break-up during four visual tasks. Optom Vis Sci 86:E106-114.

Karson CN (1983) Spontaneous eye-blink rates and dopaminergic systems. Brain 106:643-653.

Karson CN (1988) Physiology of normal and abnormal blinking. Adv Neurol 49:25-37.

Karson CN, Berman KF, Donnelly EF, Mendelson WB, Kleinman JE, Wyatt RJ (1981a) Speaking, thinking, and blinking. Psychiatry Res 5:243-246.

Karson CN, Staub RA, Kleinman JE, Wyatt RJ (1981b) Drug effect on blink rates in rhesus monkeys: preliminary studies. Biol Psychiatry 16:249-254.

Karson CN, Bigelow LB, Kleinman JE, Weinberger DR, Wyatt RJ (1982a) Haloperidol-induced changes in blink rates correlate with changes in BPRS score. Br J Psychiatry 140:503-507.

Karson CN, LeWitt PA, Calne DB, Wyatt RJ (1982b) Blink rates in parkinsonism. Ann Neurol 12:580-583

Karson CN, Kleinman JE, Berman KF, Phelps BH, Wise CD, DeLisi LE, Jeste DV (1983) An inverse correlation between spontaneous eye-blink rate and platelet monoamine oxidase activity. Br J Psychiatry 142:43-46.

King-Smith PE, Fink BA, Hill RM, Koelling KW, Tiffany JM (2004) The thickness of the tear film. Curr Eye Res 29:357-368.

Kleven MS, Koek W (1996) Differential effects of direct and indirect dopamine agonists on eye blink rate in cynomolgus monkeys. J Pharmacol Exp Ther 279:1211-1219.

Kliem MA, Maidment NT, Ackerson LC, Chen S, Smith Y, Wichmann T (2007) Activation of nigral and pallidal dopamine D1-like receptors modulates basal ganglia outflow in monkeys. J Neurophysiol 98:1489-1500.

Korosec M, Zidar I, Reits D, Evinger C, Vanderwerf F (2006) Eyelid movements during blinking in patients with Parkinson's disease. Mov Disord 21:1248-1251.

Lawrence MS, Redmond DE Jr (1991) MPTP lesions and dopaminergic drugs alter eye blink rate in African green monkeys. Pharmacol Biochem Behav 38:869-874.

Leblois A, Wendel BJ, Perkel DJ (2010) Striatal dopamine modulates basal ganglia output and regulates social context-dependent behavioral variability through D1 receptors. J Neurosci 30:5730-5743.

Lorber M (1993) Regional differences within the external 'duct' of the rat exorbital lacrimal gland. Exp Eye Res 56:471-480.

Middleton JW, Chacron MJ, Lindner B, Longtin A (2003) Firing statistics of a neuron model driven by long-range correlated noise. Phys Rev E Stat Nonlin Soft Matter Phys 68:021920.

Montés-Micó R, Alió JL, Muñoz G, Charman WN (2004) Temporal changes in optical quality of air-tear film interface at anterior cornea after blink. Invest Ophthalmol Vis Sci 45:1752-1757.

Naase T, Doughty MJ, Button NF (2005) An assessment of the pattern of spontaneous eyeblink activity under the influence of topical ocular anaesthesia. Graefes Arch Clin Exp Ophthalmol 243:306-312.

Nakamori K, Odawara M, Nakajima T, Mizutani T, Tsubota K (1997) 
Blinking is controlled primarily by ocular surface conditions. Am J Ophthalmol 124:24-30.

Nakano T, Yamamoto Y, Kitajo K, Takahashi T, Kitazawa S (2009) Synchronization of spontaneous eyeblinks while viewing video stories. Proc Biol Sci 276:3635-3644.

Németh J, Erdélyi B, Csákány B, Gáspár P, Soumelidis A, Kahlesz F, Lang Z (2002) High-speed videotopographic measurement of tear film build-up time. Invest Ophthalmol Vis Sci 43:1783-1790.

Orchard LN, Stern JA (1991) Blinks as an index of cognitive activity during reading. Integr Physiol Behav Sci 26:108-116.

Panneton WM, Burton H (1981) Corneal and periocular representation within the trigeminal sensory complex in the cat studied with transganglionic transport of horseradish peroxidase. J Comp Neurol 199:327-344.

Pellegrini JJ, Horn AK, Evinger C (1995) The trigeminally evoked blink reflex. I. Neuronal circuits. Exp Brain Res 107:166-180.

Pivik RT, Dykman RA (2004) Endogenous eye blinks in preadolescents: relationship to information processing and performance. Biol Psychol 66:191-219.

Ponder E, Kennedy WP (1927) On the act of blinking. Exp Physiol 18:89-110.

Powers AS, Schicatano EJ, Basso MA, Evinger C (1997) To blink or not to blink: inhibition and facilitation of reflex blinks. Exp Brain Res 113:283-290.

Schicatano EJ, Peshori KR, Gopalaswamy R, Sahay E, Evinger C (2000) Reflex excitability regulates prepulse inhibition. J Neurosci 20:4240-4247.

Schicatano EJ, Mantzouranis J, Peshori KR, Partin J, Evinger C (2002) Lid restraint evokes two types of motor adaptation. J Neurosci 22:569-576.

Schlote T, Kadner G, Freudenthaler N (2004) Marked reduction and distinct patterns of eye blinking in patients with moderately dry eyes during video display terminal use. Graefes Arch Clin Exp Ophthalmol 242:306-312.

Shigenaga Y, Chen IC, Suemune S, Nishimori T, Nasution ID, Yoshida A, Sato H, Okamoto T, Sera M, Hosoi M (1986) Oral and facial representation within the medullary and upper cervical dorsal horns in the cat. J Comp Neurol 243:388-408.

Sibony, PA, Evinger, C (1998) Normal and abnormal eyelid function. In: Walsh and Hoyt's clinical neuro-ophthalmology (Miller, NR, Newman, NJ, eds), pp 1509-1594. Baltimore: Williams and Wilkins.

Snedecor, GW, Cochran, WG (1967) Statistical methods. Ames, IA: The Iowa State University.
Stern JA, Walrath LC, Goldstein R (1984) The endogenous eyeblink. Psychophysiology 21:22-33.

Svoboda KR, Fetcho JR (1996) Interactions between the neural networks for escape and swimming in goldfish. J Neurosci 16:843-852.

Taylor JR, Elsworth JD, Lawrence MS, Sladek JR Jr, Roth RH, Redmond DE Jr (1999) Spontaneous blink rates correlate with dopamine levels in the caudate nucleus of MPTP-treated monkeys. Exp Neurol 158:214-220.

Tsubota K, Nakamori K (1993) Dry eyes and video display terminals. N Engl J Med 328:584

Tsubota K, Nakamori K (1995) Effects of ocular surface area and blink rate on tear dynamics. Arch Ophthalmol 113:155-158.

Tsubota K, Hata S, Okusawa Y, Egami F, Ohtsuki T, Nakamori K (1996) Quantitative videographic analysis of blinking in normal subjects and patients with dry eye. Arch Ophthalmol 114:715-720.

van Ham JJ, Yeo CH (1996) The central distribution of primary afferents from the external eyelids, conjunctiva, and cornea in the rabbit, studied using WGA-HRP and B-HRP as transganglionic tracers. Exp Neurol 142:217-225.

Walcott B, Birzgalis A, Moore LC, Brink PR (2005) Fluid secretion and the $\mathrm{Na}+-\mathrm{K}+-2 \mathrm{Cl}$ - cotransporter in mouse exorbital lacrimal gland. Am J Physiol Cell Physiol 289:C860-867.

Weiss C, Disterhoft JF (2008) Evoking blinks with natural stimulation and detecting them with a noninvasive optical device: a simple, inexpensive method for use with freely moving animals. J Neurosci Methods 173:108-113.

Wichmann T, DeLong MR (2003) Pathophysiology of Parkinson's disease: the MPTP primate model of the human disorder. Ann N Y Acad Sci 991:199-213.

Williams DL (2002) Ocular disease in rats: a review. Vet Ophthalmol 5:183-191.

Zaman ML, Doughty MJ (1997) Some methodological issues in the assessment of the spontaneous eyeblink frequency in man. Ophthalmic Physiol Opt 17:421-432.

Zaman ML, Doughty MJ, Button NF (1998) The exposed ocular surface and its relationship to spontaneous eyeblink rate in elderly caucasians. Exp Eye Res 67:681-686. 